\title{
El trasvase de desigualdades de clase y etnia entre mujeres: los servicios de proximidad ${ }^{1}$
}

\author{
Sònia Parella Rubio
}

Universitat Autònoma de Barcelona. Departament de Sociologia

08193 Bellaterra (Barcelona). Spain

sparella@selene.uab.es

\section{Resumen}

La concentración de las mujeres immigrantes extracomunitarias en los servicios de proximidad hace efectiva la triple discriminación laboral — por razón de clase social, género y etnia - a la que se enfrenta este colectivo en la sociedad receptora. El artículo pretende explicar esta posición en el mercado de trabajo a partir del estudio del «contexto de recepción", teniendo en cuenta la influencia de los factores institucionales y, en especial, el análisis de la estructura de la demanda del mercado de trabajo. La adopción de la perspectiva de género a lo largo del análisis, pone en evidencia las relaciones patriarcales y el trasvase de cargas reproductivas entre mujeres de distinta clase social y origen étnico.

Palabras clave: servicios de proximidad, género, triple discriminación, inmigración extracomunitaria, contexto de recepción.

Abstract. The transfer of class and ethnic group inequalities among women: the caring jobs

The concentration of non-EU immigrant women in «caring jobs» indicates a triple labour discrimination - based on social class, gender and ethnic group — in the receiving society. The article gives a general overview of the position of non-EU immigrant women in the Spanish labour market, from the analysis of «reception context», taking into consideration the influence of institutional factors and, particularly, the structure of the labour demand. The adoption of a gender perspective throughout the analysis evidences patriarchal relationships and the transfer of reproductive work among women from different social class and ethnic group.

Key words: caring jobs, gender, triple labour discrimination, non-EU immigration, reception context.

1. Este artículo recoge parte de los resultados de la Memoria de Doctorado titulada La internacionalización de la reproducción o el trasvase de desigualdades de clase y etnia entre mujeres. La mujer inmigrante en los «servicios de proximidad» en España, presentada en el Departamento de Sociología de la Universitat Autònoma de Barcelona y dirigida por la doctora Carlota Solé, a la que agradezco sus consejos y todo su apoyo. 


\section{Sumario}

1. Introducción

2. Feminización de los flujos migratorios e inserción laboral de la mujer inmigrante en los servicios de proximidad

3. El contexto de recepción: un mercado de trabajo sexuado

4. El contexto de recepción: la demanda de servicios de proximidad como respuesta a «nuevas» necesidades sociales
5. El contexto de recepción: los factores institucionales

6. La mujer inmigrante en los servicios de proximidad y la triple discriminación laboral

Bibliografía

\section{Introducción}

El principal objetivo de este artículo es estudiar la migración femenina desde la perspectiva de la triple discriminación laboral — por razón de clase, género y etnia - a la que se enfrenta este colectivo en la sociedad de acogida, a partir del análisis de la inserción laboral de la mujer inmigrante en los servicios de proximidad o servicios de la vida diaria, que pueden definirse como aquellas actividades remuneradas destinadas a satisfacer las necesidades de las personas y de las familias, que aparecen, en la actualidad, en la vida cotidiana de las sociedades occidentales (Torns, 1996). Algunos de estos servicios están fuertemente vinculados al cuidado de las personas (sobre todo de ancianos y enfermos) y otros tienen que ver con la esfera doméstica (trabajo doméstico a domicilio, gestión del hogar) (Torns, 1997, 1999a).

La Comisión Europea (1995) destaca la rápida expansión que han experimentado este tipo de servicios en Europa, con una tasa de crecimiento anual que se sitúa entre el 4\% y el 7\%. Ello les convierte en uno de los ámbitos de creación de empleo más activos dentro de los denominados «nuevos yacimientos de empleo», que engloban las nuevas ocupaciones que están surgiendo en el capitalismo avanzado para satisfacer nuevas necesidades y dar respuesta a las transformaciones sociales (Torns, 1997). El crecimiento de los servicios de proximidad se debe a la creciente externalización del trabajo reproductivo por parte de las nuevas clases medias urbanas de las sociedades occidentales. De hecho, la mercantilizacion del trabajo doméstico-familiar siempre ha existido, de la mano de la figura del criado o criada y del servicio doméstico - éste último, nutrido en España básicamente de mujeres jóvenes procedentes de áreas rurales - Sin embargo, su incremento masivo actual tiene mucho que ver con los cambios sociodemográficos y económicos ocurridos en las últimas décadas en las sociedades occidentales, tales como el envejecimiento de la población, la creciente participación femenina en el mercado de trabajo, una nueva gestión del tiempo en el interior del núcleo familiar y, por último, la crisis fiscal del Estado del bienestar en el marco del neoliberalismo predominante.

Dicho proceso de externalización de las tareas de reproducción social genera «nuevas» ocupaciones, caracterizadas por la precariedad, el desprestigio social 
y la invisibilidad, que no son absorbidas por la mujer trabajadora autóctona, lo que genera una creciente demanda de mujeres inmigrantes extracomunitarias para llevarlas a cabo. Es en este contexto en el que debe enmarcarse la creciente feminización de los flujos migratorios hacia España. La demanda de fuerza de trabajo en los servicios de proximidad constituye un claro exponente de las tesis de Sassen (1993), según las cuales la transformación de las economías en los países occidentales genera, especialmente en las grandes ciudades y en las global cities, concentraciones considerables de trabajo de servicios mal remunerados para sostener los nuevos estilos de vida de la creciente mano de obra profesional (servicio doméstico, otros servicios personales...). Esta situación corre el riesgo de convertir los servicios de proximidad, profundamente asociados a la precariedad, la invisibilidad, el desprestigio social y la servitud, en un «nicho laboral» para las mujeres inmigrantes, con el consiguiente trasvase de desigualdades de clase y etnia dentro del propio colectivo de mujeres (Torns, 1996, 1997, 1999a).

Con el objetivo de analizar los condicionantes de la ubicación de la mujer inmigrante en los servicios de proximidad, se aplica aquí la propuesta teórica de Portes y Böröcz (1992). Ambos autores mantienen que la incorporación de los inmigrantes en la sociedad receptora depende sólo parcialmente de las características de los inmigrantes, de modo que sus distintas trayectorias laborales se explican, básicamente, a partir de una serie de factores contextuales que configuran el "contexto de recepción», junto a la influencia de las comunidades étnicas preexistentes o redes sociales, que no van a ser tratadas en estas páginas $^{2}$. Las características del mercado de trabajo español, la estructura de la demanda y los contenidos de la política migratoria son los principales factores contextuales y constituyen el eje central del artículo.

Aunque la perspectiva del «contexto de recepción».puede resultar excesivamente determinista y difumina la heterogeneidad de trayectorias laborales, circunstancias y orígenes de las mujeres inmigrantes, constituye un instrumento conceptual eficaz, capaz de destacar los factores estructurales que influyen en el conjunto de mujeres inmigrantes, sin que ello signifique que todas ellas se conviertan automáticamente en "víctimas», condenadas a la explotación, y que no existan estrategias individuales capaces de superar todos estos condicionantes o parte de ellos.

Este artículo recoge la primera fase de una investigación todavía no concluida, por lo que los resultados presentados sólo proceden de las fuentes estadísticas, concretamente de las estadísticas de permisos de trabajo a trabajadores extranjeros y de la Encuesta de Población Activa (EPA) ${ }^{3}$. La inexistencia de

2. Un estudio pionero en la aplicación del «contexto de recepción» al análisis de la inserción laboral de la población inmigrante en España lo constituye la tesis doctoral de Herranz (1996).

3. En una fase posterior del estudio se llevarán a cabo «grupos de discusión» con mujeres inmigrantes que trabajan en los servicios de proximidad y con las mujeres autóctonas que consumen dichos servicios. 
datos sobre el número de trabajadoras inmigrantes asalariadas en empresas de servicios de proximidad y el hecho de que la mayor parte de los empleos de este colectivo tengan lugar bajo el régimen de dependencia persona a persona ${ }^{4}$ y no en empresas de servicios, ha determinado que en este estudio sólo se utilicen los permisos de trabajo en el servicio doméstico como indicador de la presencia de las mujeres inmigrantes en los servicios de proximidad. Por lo tanto, van a estudiarse aquellas trabajadoras que prestan sus servicios en el hogar del empleador, a cambio de una retribución monetaria y/o en especie. Esta opción sólo recoge una parte de los servicios de proximidad; justamente aquellas actividades con mayor connotación servil —el cuidado de las personas y el trabajo doméstico a domicilio-, dejando al margen muchas nuevas ocupaciones en empresas de servicios que están surgiendo alrededor de estas «nuevas» necesidades y que van a ser recogidas en futuras fases del estudio.

\section{Feminización de los flujos migratorios e inserción laboral de la mujer inmigrante en los servicios de proximidad}

En España, desde mediados de los ochenta, se asiste a una feminización de los flujos migratorios extracomunitarios, de manera que constituyen el $44,1 \%$ del total de residentes extranjeros en el Régimen General a 31/12/1997 (OPI, 1998). La composición de las mujeres extracomunitarias residentes según nacionalidades nos muestra el marcado predominio de las mujeres marroquíes (con un $26,1 \%$ del total de mujeres), a pesar de que no se trata de un flujo especialmente feminizado, seguidas de mujeres procedentes de distintos países latinoamericanos (Perú, República Dominicana, Colombia), con flujos migratorios fuertemente feminizados y, en menor medida, de las mujeres filipinas y de las mujeres chinas (OPI, 1998). La elevada tasa de actividad de estas mujeres inmigrantes y el hecho de que con frecuencia emigren solas, siendo pioneras del proceso migratorio, indica que no siempre se trata de una inmigración sólo de arrastre, sino también de mujeres que han emigrado por consideraciones básicamente económicas.

El análisis de las principales ramas de actividad en las que se insertan los hombres y las mujeres inmigrantes con permiso de trabajo permite detectar una fuerte segregación ocupacional por sexos. Es decir, al reducido abanico de actividades a las que están relegados los y las trabajadoras inmigrantes, debe añadírsele la segregación ocupacional por razones de género, situando a las mujeres en el último escalafón de la estructura ocupacional: el servicio doméstico. Los datos muestran un $47,7 \%$ del total de las mujeres trabajadoras ocupadas en el servicio doméstico y un $8,2 \%$ en la hostelería. Los trabajadores masculinos, por el contrario, presentan una mayor dispersión de actividades que las mujeres, repartiéndose entre la agricultura $(15,7 \%)$, la construcción $(10,7 \%)$, la hostelería $(10,1 \%)$, el comercio $(9,8 \%)$ y el servicio doméstico

4. Régimen Especial de Empleados de Hogar de la Seguridad Social. 
(6,3\%) (OPI, 1998). La feminización del servicio doméstico se hace todavía más patente al comprobar que el $84,4 \%$ de los extranjeros afiliados y en alta en el Régimen Especial de Empleados de Hogar de la Seguridad Social son mujeres (OPI, 1999). Pero el volumen de mujeres inmigrantes que trabajan en el servicio doméstico difícilmente puede estimarse a partir de los permisos de trabajo concedidos, puesto que existe un importante colectivo de mujeres inmigrantes irregulares que trabajan en el sector sin contrato de trabajo y que no aparecen contabilizadas en las estadísticas.

A pesar de la pluralidad de cronologías, circunstancias, trayectorias laborales, orígenes geográficos, económicos, sociales y culturales que presentan las mujeres inmigrantes en España, en la que no se detiene este artículo, los datos presentados sugieren la existencia de una serie de condicionantes estructurales que inciden de manera específica en el conjunto del colectivo de mujeres trabajadoras extracomunitarias, relegándolas a un «nicho laboral» muy concreto del mercado de trabajo: los servicios de proximidad. El uso del «contexto de recepción» como instrumento conceptual, que a continuación se presenta, permite identificar cuáles son estos condicionantes y de qué modo se hace efectiva su influencia.

\section{El contexto de recepción: un mercado de trabajo sexuado}

Sin ánimos de ofrecer un análisis exhaustivo de las características del mercado de trabajo español, sí vamos a enumerar brevemente los aspectos que hacen posible comprender el marco estructurador de la situación laboral de las mujeres inmigrantes en España.

La llegada del modelo de acumulación basado en la «flexibilidad», así como la preeminencia del sector terciario, el aumento del nivel educativo de la población activa — sobre todo de las mujeres - y la incapacidad de generar un nivel de empleo adecuado al crecimiento de la población en edad de trabajar, constituyen los rasgos más destacados. Como consecuencia, la tasa de paro española supera con creces la media europea y en los últimos años se ha asistido a una rápida precarización del empleo, por medio de la proliferación de contratos de trabajo a tiempo determinado, de la facilitación de los despidos y de la extensión de la economía informal (Prieto, 1994; Martín Artiles, 1997).

Este contexto de precarización y segmentación del mercado de trabajo es el marco en el que tiene lugar la discriminación laboral de la población inmigrante y su ubicación en los escalafones más bajos de la estructura ocupacional o «etnoestratificación» del mercado de trabajo. En primer lugar, los trabajadores inmigrantes están destinados a aceptar aquellas actividades rechazadas por una fuerza de trabajo española cada vez más exigente en sus apetencias y menos proclive a realizar trabajos manuales no cualificados, arriesgados, sucios y mal pagados, a pesar de la fuerte incidencia del paro. En segundo lugar, la fuerza de trabajo inmigrante tiene acceso a ocupaciones en las que los autóctonos también concurren, pero los inmigrantes son discriminados positiva- 
mente por el hecho de aceptar peores condiciones de trabajo — muchas veces bajo formas de economía informal-, lo que permite el abaratamiento de costes, alcanzar mayor flexibilidad y frenar la inflación (Solé, 1995).

Pero para la mujer inmigrante, a su condición de inmigrante en el mercado de trabajo deben añadírsele, además, las desigualdades de género de la que son víctimas el conjunto de mujeres en la sociedad receptora. A pesar del acelerado aumento de la participación femenina en el mercado de trabajo desde 1985, con una tasa de actividad que ha crecido del 30,9\% en 1987 al $37,6 \%$ en 1997, según datos de la EPA, las desigualdades de género siguen presentes, desde el momento en que la tasa de actividad femenina es una de las más bajas de la UE y que buena parte del aumento de mujeres activas ha ido directamente a engrosar las filas del paro - con un 52,8\% de mujeres dentro de la población en paro y con una tasa de paro femenina de $28,3 \%$, que casi dobla a la masculina (16,1\%), en base a los datos de la EPA de 1997.

Las mujeres son discriminadas en el mercado de trabajo de las sociedades occidentales en base a la asunción patriarcal que considera que el rol natural de la mujer está en la esfera reproductiva, por lo que va a ser menos productiva que un hombre en determinados trabajos remunerados y, además, su actividad se va a ver negativamente afectada por sus responsabilidades familiares, en términos de movilidad, estabilidad y eficiencia. La concentración primordial de la mujer en el área de la reproducción la convierte en trabajadora secundaria o ausente en el área de la producción.

Pero al margen de la fuerte incidencia de la inactividad y del paro entre las mujeres occidentales, los procesos de terciarización han ido acompañados de una fuerte feminización del mercado de trabajo español — sobre todo en los servicios poco cualificados - que ha permitido evidenciar todavía más los procesos de segregación ocupacional que padecen las mujeres. El 63\% de las mujeres ocupadas se concentran en seis sectores de actividad (comercio y reparaciones, sanidad y servicios sociales, enseñanza, inmobiliaria y servicios a empresas, hostelería y servicio doméstico), según datos de la EPA de 1997. Se trata, sin lugar a dudas, de sectores de actividad con una fuerte tasa de feminización. Este proceso de segregación horizontal es el resultado de la existencia de actividades consideradas "femeninas" en el imaginario social, en las que mayormente las mujeres prolongan sus habilidades como madres, esposas y cuidadoras, adquiridas a través de la socialización diferencial de género. Las mujeres trabajadoras se sitúan así en los estratos más bajos de la estructura ocupacional, en aquellas actividades más precarizadas, menos remuneradas y menos valoradas socialmente, Además de la segregación, otros rasgos que acompañan la mayor presencia femenina en el mercado de trabajo español son la discriminación salarial (Peinado, 1991) y su sobrerrepresentación en los contratos de trabajo «atípicos» (temporalidad y tiempo parcial), así como en la economía informal (Torns, 1999a).

Estos datos dibujan un escenario en el que, según Torns (1998: 42), «la imagen del obrero fordista-taylorista desaparece y va siendo substituida por un empleado de los servicios [...] ese empleado es en su mayoría una empleada 
que, dado el cambio de género, siempre tiene peores salarios y peores condiciones de trabajo». En consecuencia, no es que la mujer, como grupo subordinado que intenta acceder al mercado de trabajo — al igual que los colectivos de jóvenes y de inmigrantes_-, sea reclutada para aquellas ocupaciones más subordinadas, existentes a priori, sino que es el propio mercado de trabajo el que se estructura a partir de las relaciones patriarcales, de manera que tanto las relaciones laborales (contratos a tiempo parcial, temporalidad...), como las condiciones de trabajo (salarios, posibilidades de promoción...) se definen y redefinen constantemente en función del género.

\section{El contexto de recepción: la demanda de servicios de proximidad como respuesta a «nuevas» necesidades sociales}

Las razones que explican el crecimiento de la demanda de los servicios de proximidad se derivan del incremento de una serie de necesidades de servicios encuadrables bajo la idea de "proximidad» (personal y familiar). Estas necesidades obedecen a una serie de factores, entre los que destacan los cambios ocurridos en la familia, a consecuencia de la creciente participación femenina en el mercado de trabajo; los cambios sociodemográficos, de los que el envejecimiento de la población es el principal protagonista y, finalmente, la crisis del Estado del bienestar (Torns, 1995, 1997; Lallement, 1998). Para comprender la creciente demanda en torno a los servicios de proximidad, debe analizarse la dificultad de compatibilizar la doble adscripción de la mujer autóctona a la esfera productiva y a la reproductiva. Es aquí donde aparecen «nuevos» espacios para la ocupación de mujeres inmigrantes.

Los cambios políticos, sociales y económicos acontecidos en los últimos años han provocado importantes transformaciones en la familia española, sobre la base de la emancipación del colectivo de mujeres. La generación de mujeres españolas de menos de cuarenta años ha protagonizado una verdadera revolución, tanto en el terreno laboral como en el reproductivo (Garrido, 1992). A pesar de la baja tasa de actividad femenina en España, ésta presenta una gran variabilidad por edades, de modo que mientras que un $74,5 \%$ de las mujeres entre 25 y 29 años son activas, las que tienen entre 50 y 54 años no alcanzan el $36 \%$ (frente a un $88,6 \%$ de tasa de actividad masculina para estas edades), según datos de la EPA de 1997. Se asiste, pues, a una clara ruptura generacional. La confluencia de los cambios políticos y económicos en ciertos períodos convierte la edad en una variable clave para comprender la forma en que las mujeres se integran en la sociedad. Sin lugar a dudas, la expansión del sistema educativo constituye uno de los elementos más determinantes, puesto que la participación femenina en el auge de la enseñanza formal es el instrumento clave para entender su inserción activa en la producción extradoméstica (Garrido, 1992).

Pero de todo ello no debe inferirse que la incorporación de la mujer al mercado de trabajo se haya producido en las últimas décadas. De hecho, la gran mayoría de mujeres de clase baja han realizado desde la industrialización diver- 
sos trabajos remunerados (en las fábricas, de sirvientas...). Lo que sí es nuevo es el cambio cultural profundo que tiene lugar a partir de los años sesenta, con el resultado de que las mujeres pasen de trabajar por necesidad a hacerlo básicamente por elección. Hasta entonces, el modelo de trabajo de la mujer (de clase media) implicaba casarse y quedarse en casa, ejerciendo de esposa y madre, de manera que se impuso el ethos de la familia burguesa y de la mujer ama de casa. El empleo voluntario de la mujer casada era visto como algo vergonzoso que significaba el abandono de sus responsabilidades familiares. Con la «revolución silenciosa» de las mujeres cae la tasa de fecundidad, aumenta su acceso a la educación superior y la clase media femenina pasa a participar activamente en el mercado laboral, de modo que se liberan de muchas de las predeterminaciones atribuidas al género femenino (Carrasco, 1998). Las nuevas generaciones de mujeres jóvenes se incorporan al mercado de trabajo y ya no están dispuestas a abandonar sus empleos en el momento de formar una familia. Estas mujeres, a diferencia de sus predecesoras, desean compatibilizar sus aspiraciones familiares con sus aspiraciones profesionales, y ya no de forma secuencial, sino simultáneamente, a sabiendas de que las posibilidades de reincorporación al mercado de trabajo tras una ruptura de la biografía laboral son limitadas (Meil, 1995).

Una de las cuestiones estratégicas es la forma en que la mujer compatibiliza la dedicación al trabajo en el mercado laboral y en el hogar. Contrariamente a las perspectivas optimistas que prevalecen en los años sesenta, en las que se cree que el desarrollo de la actividad femenina y la independencia económica de las mujeres conllevará nuevos repartos de tareas, la distribución de tareas entre hombres y mujeres ha sufrido pocos cambios (Fougeyrollas-Schwebel, 1995). Mientras las mujeres invierten su tiempo entre familia y trabajo remunerado, con una percepción del tiempo circular, el hombre sigue manteniendo su participación exclusiva en el mercado laboral, alternándolo con los momentos de ocio. La mujer se ve irremediablemente condenada a realizar una doble jornada, con lógicas de organización incompatibles entre sí, y a padecer el estrés psicológico que esta situación genera, conocida como «doble presencia» (Balbo, 1994). Aunque entre las generaciones más jóvenes y con mayor nivel educativo se observan mayores cotas de igualdad entre hombres y mujeres en la esfera reproductiva y una separación de roles no tan rígida, todavía queda mucho camino por recorrer. Las nuevas generaciones masculinas son conscientes de que deben colaborar en el hogar, pero el problema reside en que esta actitud se limita a ofrecer una «ayuda» puntual, y es la mujer la que señala cuáles son las tareas a desempeñar y cómo deben realizarse. Por lo tanto, a pesar del discurso de que lo «correcto» es romper con la división sexual del trabajo, la práctica cotidiana lo contradice. Diversos estudios sobre usos del tiempo y desigualdad entre hombres y mujeres confirman esta constatación (Izquierdo, 1988; Ramos, 1990; Page, 1996; Carrasco, 1997). Por lo tanto, puede concluirse que la mayor participación de la mujer en la esfera productiva en los últimos años supone una reducción de su presencia horaria en la vida familiar, sin una paralela reducción de las cargas domésticas. 
De ese modo, la transferencia de tareas y de responsabilidades reproductivas se acaba efectuando entre las propias mujeres de la familia y las mujeres en general, trazándose una especie de división del trabajo entre las mujeres a lo largo del ciclo vital (Fougeyrollas-Schewebel, 1995: 94) Buena parte de las tareas reproductivas son asumidas por las mujeres de más de cuarenta años, ya sea cuidando a sus nietos o a las personas mayores dependientes. Se trata de mujeres que o bien no han trabajado nunca de manera remunerada, o bien están jubiladas.

La demanda de servicios de proximidad o servicios de la vida diaria nace del conflicto ante la dificultad de conciliar ambas «presencias» y la necesidad de responder a las exigencias diarias del trabajo reproductivo. Es en este contexto donde se plantea la mercantilización o externalización de lo que hasta ahora había sido simplemente trabajo no remunerado, por parte de las mujeres trabajadoras de clase media. La falta de un reparto equitativo de las tareas reproductivas provoca el declive de la idealizada complementariedad de los roles conyugales segregados y se hace visible la importancia del trabajo domésticofamiliar o reproductivo para satisfacer las necesidades de las personas. Entre los sectores de la población con más nivel educativo se asiste a una nueva gestión del tiempo en el interior del núcleo familiar y a un nuevo concepto de "calidad de vida», de manera que resulta más práctico y menos conflictivo recurrir al trabajo externo para llevar a cabo las tareas reproductivas, que intentar distribuirlas entre hombres y mujeres dentro de la unidad familiar. De esa manera, el recurso a los servicios de proximidad no contribuye sólo a suavizar la sobrecarga laboral de la mujer, sino también a paliar los conflictos entre la pareja y mantener la cohesión familiar.

En base a los resultados obtenidos en una encuesta a los hogares catalanes, si bien la autoproducción de los servicios habituales a las personas y hogares es la tónica dominante, el grado de insatisfacción supera el $10 \%$ en la atención a personas dependientes y en la limpieza del hogar, lo que genera un importante potencial de demanda insatisfecha futura que van a cubrir los servicios de proximidad (Jiménez, 1999).

Por lo tanto, determinadas labores reproductivas son rechazadas también por las mujeres, a consecuencia de su escasa valoración, y son transferidas, aunque sin dejar de supervisarlas, a otras mujeres con menos recursos económicos, a cambio de más tiempo para la familia o el ocio, o de mayor dedicación al trabajo fuera del hogar, en un mercado laboral cada vez más competitivo y «masculinizado». La pregunta clave es saber quién va a realizar estas tareas de «servidor». El incremento del nivel educativo de las mujeres autóctonas ha aumentado su «nivel de aceptación» de las condiciones de trabajo por debajo del cual tenderían a considerar sus oportunidades de empleo "socialmente» inaceptables (Villa, 1990: 312). A las mujeres de las clases medias urbanas,

5. Encuesta realizada en 1998 por la Fundació CIREM, en el marco del Libro Blanco de los Nuevos Yacimientos de Ocupación en Catalunya. 
con un nivel de formación reglada elevado, el mercado laboral les ofrece mejores oportunidades de trabajo que hace unos años y, a pesar de las elevadas tasas de paro que acechan al colectivo femenino, no están dispuestas a realizar unas actividades, los servicios de proximidad, que son socialmente consideradas una prolongación del trabajo reproductivo y que resultan emblemáticas de la discriminación por razón de género. Por lo tanto, la demanda de empleadas domésticas crece al mismo tiempo que disminuye la oferta. Es aquí donde aparece un «nicho laboral» que van a ocupar las mujeres autóctonas con menos recursos económicos y, en especial, las mujeres inmigrantes, que llegan a España atraídas por la fuerte demanda. En consecuencia, los servicios de proximidad están muy lejos de la metáfora "yacimientos de empleos», cargada de ideología, ya que en el fondo no son más que una transferencia del servicio doméstico tradicional (Lallement, 1998).

Otra fuente importante de necesidades por satisfacer es el resultado del proceso de envejecimiento de la población que atenaza a todas las sociedades industrializadas. Para el conjunto de la UE, en 1992 había un 13,5\% de la población con más de 65 años (Laville, 1992: 353). En base a cifras aproximadas del censo de población de 1991, las personas mayores de 65 años suponen prácticamente el $14 \%$ de la población española y un total de 5,5 millones de individuos (INSERSO, 1995a: 31). Según datos de una encuesta realizada por el CIS en $1997^{6}$, alrededor del $27 \%$ de las personas mayores requieren de algún tipo de ayuda de otra persona para poder realizar alguna de las actividades de su vida cotidiana (vestirse, lavarse, ir al servicio, tomar medicación, andar, realizar las tareas domésticas...). Este porcentaje constituye una clara aproximación a la dependencia de este colectivo, así como a la importancia de la contribución de la familia en este ámbito. En un Estado del bienestar como el español, en el que las tareas de cuidado no han sido asumidas por los servicios sociales públicos y en el que la tasa de actividad femenina aumenta aceleradamente en las generaciones de mujeres más jóvenes, a corto plazo va a producirse una escasez de mujeres «disponibles» para poder ocuparse directamente de las personas mayores. Cada vez es más frecuente que las familias de las clases medias urbanas, con ambos cónyuges trabajando en el mercado de trabajo, precisen de trabajadoras domésticas para atender a las personas mayores, asistiéndose a una creciente mercantilización de las tareas de cuidado ${ }^{7}$.

Un tercer factor es el incremento de la demanda de servicios clásicos del Estado del bienestar, vinculados a la atención de los niños y al cuidado de las personas adultas dependientes. Este aumento de la demanda choca con la revisión del Estado del bienestar que está teniendo lugar en toda Europa desde los años setenta, a partir de la concienciación sobre los límites del conjunto de prestaciones que han ido asumiendo los poderes públicos y el redescubrimiento

6. Citada en CES (1997).

7. Según datos del INSERSO (1995b), alrededor de un 6\% de las personas mayores dependientes recibe ayuda remunerada procedente de una trabajadora doméstica. 
de la familia como alternativa menos costosa y más eficaz para atender a las personas que requieren cuidados ${ }^{8}$. Las políticas de ajuste y de contención del gasto público suponen una reducción significativa del gasto social en este tipo de servicios. En un Estado del bienestar poco desarrollado como el español, basado en un régimen del bienestar profundamente "familista»", las actuales tendencias familiarizadoras conllevan consecuencias mucho más alarmantes para las mujeres españolas, ya que se asiste a una crisis del Estado del bienestar sin que previamente se hayan desarrollado suficientemente las prestaciones sociales. A pesar de que en el Estado del bienestar español las familias nunca han dejado de ser las proveedoras directas de buena parte de los servicios sociales —rasgo definitorio del "modelo católico» o «modelo del sur», característico de los países del sur de Europa (Abrahamson, 1995)_, la velocidad de los cambios sociales y económicos mencionados ha transformado profundamente el rol de las mujeres y la estructura familiar de la sociedad española.

\section{El contexto de recepción: los factores institucionales}

Siguiendo los planteamientos de Portes y Böröcz (1992), las actitudes de los gobiernos receptores hacia la inmigración y las medidas legales adoptadas son un eje esencial del contexto de acogida, por cuanto organizan las oportunidades vitales de las personas inmigrantes. Desde el ámbito legal se define el «campo de posibilidades» de la inserción de la fuerza de trabajo inmigrante en el mercado de trabajo, proceso denominado «discriminación institucional» (Cachón, 1995). Por el simple hecho de ser extranjero (no comunitario), las posiciones que pueden ocuparse en el mercado de trabajo están determinadas negativamente, ya sea porque el «marco institucional» fija el campo de no-circulación de la fuerza de trabajo inmigrante - a través del recurso a la «situación nacional de empleo»— o bien porque el Estado ratifica lo que el mercado ya ha fijado como campo de oportunidades laborales de los inmigrantes - a través de los contingentes-. Es así como la política migratoria favorece la reclusión de los trabajadores extranjeros en unos sectores de actividad determinados, caracterizados por presentar las peores condiciones de trabajo, contribuyendo a la flexibilización y a la etnoestratificación del mercado de trabajo.

Este «marco institucional de la discriminación» actúa de distinta manera según se trate de hombres inmigrantes o de mujeres inmigrantes, en conjunción con factores propios de las relaciones de género y con la existencia de un mercado de trabajo claramente sexuado. Uno de los efectos más destacados es

8. Abrahamson (1995) utiliza el término welfare mix o «sociedad del bienestar» para referirse al proceso de revalorización de la familia, del mercado y de las organizaciones voluntarias desde los poderes públicos, como expresión de la conveniencia de que sean varios los sectores responsables del bienestar - mercantil, estatal, informal y voluntario.

9. El concepto "familismo» hace referencia a la existencia de redes de solidaridad familiar y de parentesco, en las cuales el papel de los familiares y parientes - léase mujeres - es fundamental para garantizar el soporte, la cohesión y, en definitiva, el bienestar. 
la promoción de la migración femenina fundamentalmente de carácter laboral, como respuesta a la demanda en el mercado de trabajo de trabajadoras para determinadas actividades dentro de los servicios de proximidad. El establecimiento de un contingente anual desde 1993 inaugura esta lógica y es el ejemplo más fehaciente de que la política migratoria está regida por el imperativo de gestión del mercado de trabajo. Según Oso (1998: 118), «la política de cupos es de especial interés para el estudio de la migración femenina, puesto que supone la aceptación a nivel institucional de la existencia de una demanda de mano de obra para el servicio doméstico que será cubierta principalmente por mujeres».

Por consiguiente, el propio «marco institucional» no sólo delimita legalmente la denominada «etnoestratificación», sino que, además, es copartícipe en la configuración de un mercado de trabajo sexuado para la fuerza de trabajo inmigrante, relegando a las mujeres a las actividades típicamente «femeninas» más proclives a la invisibilidad y a la explotación. Esta situación repercute claramente en la composición de los flujos migratorios y en las estrategias migratorias, ejerciendo un efecto de atracción (pull) que sirve de estímulo para que las mujeres inmigrantes sean pioneras de la cadena migratoria, a sabiendas de que la política migratoria española les ofrece mayores posibilidades que a los hombres para regularizar su situación jurídica.

En consecuencia, el Estado recurre a la inmigración femenina del Tercer Mundo en ausencia de una política familiar adecuada que permita a la mujer trabajadora autóctona conciliar «profesión» y «familia», dada la escasez de fuerza de trabajo autóctona dispuesta a emplearse en estas tareas. Desde esta perspectiva, el reclutamiento de trabajadoras extranjeras supone «subvencionar» un servicio privado de atención de los niños y de las personas mayores dependientes (Stasiulis y Bakan, 1997).

\section{La mujer inmigrante en los servicios de proximidad y la triple discriminación laboral}

Desde una perspectiva de género y partiendo de un "contexto de recepción» basado en un mercado de trabajo profundamente segmentado por razón de la etnia, donde las mujeres son relegadas a determinadas actividades y categorías profesionales (segregación horizontal y vertical) y con una fuerte demanda de fuerza de trabajo para llevar a cabo las tareas de la reproducción social, la mujer inmigrante es triplemente discriminada en el mercado de trabajo, resultado de la articulación de los procesos de discriminación por razón de clase, género y etnia (Morokvasic, 1984; Boyd, 1984). Esta triple discriminación sitúa a la mujer inmigrante en aquellos «nichos laborales» que la mujer autóctona rechaza por ser emblemáticos de la discriminación de género, reforzándose todavía más la repartición sexuada de la ocupación y las desigualdades de clase y de etnia (Torns, 1997, 1999b). De ese modo, las trabajadoras extranjeras aparecen como recurso para llenar un vacío en el mercado laboral. 
La incorporación de la perspectiva de género al análisis de la inserción laboral de la mujer inmigrante permite constatar que, a pesar que el conjunto de la población inmigrante extracomunitaria padece la «etnoestratificación» del mercado de trabajo, el abanico de posibilidades de las mujeres inmigrantes es mucho más reducido que el de los hombres inmigrantes y son ellas las que ocupan el último escalafón: el servicio doméstico.

Por otro lado, de la comparación de la inserción laboral de las mujeres inmigrantes con la de las mujeres autóctonas se desprende que, si bien ambos colectivos son discriminados en el mercado de trabajo por razón de su género, las trabajadoras inmigrantes padecen la segregación ocupacional de manera más acuciante, ubicándose mayormente en aquellas actividades "femeninas» socialmente más desvalorizadas, mal pagadas y con una fuerte connotación «servil»: el servicio doméstico. Ello no significa que las mujeres autóctonas no estén presentes en los servicios de proximidad, sino tan solo que la concentración de trabajadoras inmigrantes en estas actividades es mucho mayor, en términos relativos, que la de mujeres autóctonas ${ }^{10}$.

Los servicios de proximidad son actividades intensivas en fuerza de trabajo, poco productivas y poco rentables, con costes laborales muy elevados. Desde una lógica meramente productivista, ciega al enorme valor social de estas tareas, los obstáculos inherentes a su mercantilización favorecen la ocupación de los grupos excluidos del mercado de trabajo - léase mujeres e inmigrantes-, bajo formas de ocupación atípicas (contratos temporales, contratos a tiempo parcial...), con un salario reducido, un fuerte desprestigio social e impregnadas de referentes doméstico-serviles.

La mujer inmigrante trabajadora es recibida en la sociedad receptora con el prejuicio de que sólo está capacitada para realizar las tareas vinculadas a la reproducción social, en base a que su condición de mujer le confiere este tipo de cualificaciones tácitas o informales, independientemente de su nivel de estudios y de su experiencia profesional previa. Por su doble condición de inmigrante procedente de países pobres y, además, mujer, se le supone un bagaje cultural similar, profundamente desvalorizado, que contrapone su carácter «tradicional» y «subdesarrollado», definido a partir de estereotipos como la "docilidad», la "paciencia» y la «subordinación", al de la mujer occidental, más moderna y emancipada (Oso, 1998). Es justamente la falta de reconocimiento de las cualificaciones que requieren muchas de estas actividades - especialmente las no vinculadas al cuidado de las personas- lo que impide su profesionalización y dificulta que las trabajadoras de estos servicios sean consideradas "profesionales que prestan servicios» y no meras «servidoras» (Torns, 1997, 1999b).

De ese modo, el empleo de mujeres inmigrantes extracomunitarias en los servicios de proximidad permite identificar un trasvase de desigualdades de

10. No debemos olvidar que el empleo de trabajadoras domésticas ha sido desde siempre una práctica distintiva de las familias con recursos económicos y que el servicio doméstico interno era un trabajo extendido entre las mujeres autóctonas de procedencia rural. 
clase y etnia entre las propias mujeres, por lo que se enmascara el mito del "nuevo igualitarismo dentro de la pareja» y el patriarcado sigue subyaciendo inalterado detrás de las estructuras domésticas y del empleo remunerado (Torns, 1995b, 1999a; Lutz, 1997). Para las mujeres de las sociedades occidentales con recursos económicos, que persiguen una carrera profesional y al mismo tiempo deben atender a su familia, recurrir a una mujer con escasos recursos económicos o a una inmigrante extracomunitaria se presenta como la mejor solución para mercantilizar parte del trabajo reproductivo y proveerse de un servicio barato que, de otra forma, no tendrían.

\section{Bibliografía}

ABRAHAMSON, P. (1995). «Regímenes europeos del bienestar y políticas sociales europeas: ¿Convergencia de solidaridades?». En SARASA. S.; MORENO, L. (eds.). El Estado del Bienestar en la Europa del Sur. Madrid: CSIC.

Ambrosini, M. (1998). «Intereses ocultos: La incorporación de los inmigrantes en la economía informal». Migraciones, núm. 4.

BoYD, M. (1984). «At a disadvantage: The occupational attainments of foreign born women in Canada». International Migration Review, vol. 18, núm. 4.

CACHÓN, L. (1995). «Marco institucional de la discriminación y tipos de inmigrantes en el mercado de trabajo en España». REIS, núm. 69.

CARrasco, C. (1997). «Mujeres, trabajo y políticas sociales en España». Revista de Estudios Feministas, núm. 13.

- (1998). "Trabajo y empleo: apuntes para una discusión no androcéntrica». En RODRíGuez Alzira, A. (ed.). Reorganización del trabajo y empleo de las mujeres. Valencia: Germania.

CES (1997). Panorama sociolaboral de la mujer en España, núm. 8.

COMISIÓN EuROPEa (1995). Iniciativas locales de desarrollo y empleo. Encuestas en la UE. Documentos de los servicios. Bruselas.

FougeYrolias-SCHWEBEL, D. (1995). «Le travail domestique: économie des servitudes et partage». En Hirata, H.; SenOtier, D. (eds.). Femmes et partage du travail. París: Syros.

GARRIDO, L. (1992). Las dos biografias de la mujer en España. Madrid: IMU.

HERRANZ, Y. (1996). «Formas de incorporación laboral de la inmigración latinoamericana en Madrid: importancia del contexto de recepción». Madrid: Universidad Autónoma de Madrid. Tesis doctoral.

INSERSO (1995a). Las personas mayores en España. Perfiles. Reciprocidad familiar. Madrid: Ministerio de Asuntos Sociales.

- (1995b). Cuidados en la vejez. El apoyo infomal. Madrid: Ministerio de Asuntos Sociales.

Instituto Nacional de Estadística (varios años). Encuesta de Población Activa. Madrid: INE.

IZQUIERDO, Ma.J. (1988). La desigualdad de la mujer en el uso del tiempo. Madrid: IMU.

JiMÉNEZ, E. (1999). «Els nous filons d'ocupació: una aproximació conceptual positiva». Àmbits de Política i Sociologia, núm. 13. 
LALlEMENT, M. (1998). «Famille et emplois de service». En MARUANI, M. (ed.). Les nouvelles frontieres de l'inégalité. Hommes et femmes sur le marché du travail. París: La Découverte/MAGE.

LAVILLE, J.L. (1992). «La création institutionnelle locale: l'exemple des services de proximité de l'inégalité. Hommes et femmes sur le marché du travail. En MARUANI, M. (ed.). París: La Découverte/MAGE.

LuTZ, H. (1997). «The Limits of European-ness. Feminist Review, núm. 57.

MarTín ARTiLes, A. (1997). «Del trabajo informal al empleo estable». Revista de Treball Social, núm. 147.

MeIL, G. (1995). «Familia y política familiar». En: Jornades sobre Família i Canvi Social. Any Internacional de la Família 1994, Barcelona.

MOROKVASIC, N. (1984). «Birds of Passage are also women». International Migration Review, vol. 18, núm. 4.

Observatorio Permanente de la Inmigración (OPI) (1998). Indicadores de la inmigración y el asilo en España, núm. 2.

- (1999). Indicadores de la inmigración y el asilo en España, núm. 3.

Oso, L. (1998). La migración hacia España de las mujeres jefas de hogar. Madrid: IMU.

PAGE, A. (1996). Los usos del tiempo como indicadores de la discriminación entre géneros. Madrid: IMU.

Peinado, M.A. (1991). «Análisis de las diferencias salariales por sexo». Revista de Economia y Sociología del Trabajo, núm. 13-14.

PORTES, A.; BÖRÖCZ, J. (1992). «Inmigración contemporánea: perspectivas teóricas sobres sus determinantes y modos de acceso». Alfoz, núm. 91-92.

PRIETO, C. (1994). Trabajadores y condiciones de trabajo. Madrid: Hoac.

Ramos, R. (1990). Cronos dividido, uso del tiempo y desigualdades entre hombres y mujeres en España. Madrid: IMU.

SASSEN, S. (1993). La movilidad del trabajo y del capital. Madrid: Ministerio de Trabajo y Seguridad Social.

Solé, C. (1995). Discriminación racial en el mercado de trabajo. Madrid: CIS.

STASIULIS, D.; BAKAN, A.B. (1997). "Negotiating Citizenship: The case of foreign domestic workers in Canada». Feminist Review, núm. 57.

TORNS, T. (1995). «Los nuevos empleos, cualificación y valoración», comunicación presentada en el Séminaire IRIS: Une vision plus large, Bruselas, junio de 1995.

- (coord.) (1996). La Formation pour les emplois de proximité. Note de reflexion au vue du rapport de genre. Bellaterra: QUIT-UAB. Informe de investigación.

- (1997). «Los servicios de proximidad, ¿un yacimiento de empleo?». Revista de Treball Social, núm. 147.

- (1998.) «Los jóvenes y los nuevos yacimientos de empleo: retos y posibilidades». Revista de Estudios de Juventud, núm. 41.

- (1999a). «Los trabajadores asalariados: desigualdades de género». En MiguÉLEZ, F; PRIETO, C. (eds.). Las relaciones de empleo en España. Madrid: Siglo XXI.

- (1999b). «El futuro del empleo femenino y los yacimientos de empleo». Comunicación presentada en la Conferencia Internacional sobre El empleo y las sociedades avanzadas. Instituto de Desarrollo Regional, Sevilla, abril de 1999. VILLA, P. (1990). La estructuración de los mercados de trabajo. Madrid: MTSS. 